\title{
Enforcement, Regulation and Development ${ }^{1}$
}

by

\author{
Jean-Jacques LAFFONT ${ }^{2}$
}

June 12, 2001

${ }^{1}$ This paper was prepared for the Nairobi May 2001 meeting of AERC.

${ }^{2}$ IDEI and ARQADE, Université des Sciences Sociales, Toulouse - France. 


\title{
Abstract \\ Enforcement, Regulation and Development \\ Jean-Jacques Laffont
}

\begin{abstract}
After discussing examples of enforcement failures for regulatory contracts in Africa, we develop a regulation model with asymmetric information and imperfect enforcement. Either the regulator succeeds in forcing the regulated firm to fulfill the contract or renegotiation takes place. The probability of renegotiation decreases with the level of enforcement expenditures which is also chosen by the regulator. We show that the endogenous level of enforcement decreases with the proneness to corruption and document empirically this relationship.
\end{abstract}

JEL Classification: D8, L5, 01.

Keywords: Regulation, Development, Enforcement, Contract. 
"There is a growing international consensus... that regulation, particularly in poor countries, must be designed with an appreciation of both information asymmetries and difficulties of enforcement"

World Development Report 2001/2.

\section{Introduction}

Regulatory contracts, as any other contractual relationships, suffer in less developed countries (LDCs) from a severe lack of enforcement. Good laws and rules are rather straightforward to import from the developed world. A good set of lawyers can transfer this institutional knowledge quite easily (if not cheaply). It is much more difficult to enforce them, because of the lack of financial and technical resources, because of the corruption of enforcement institutions, and because of the weak bargaining position of regulators.

The vital role of enforcement for laws, rules and contracts was stressed first by the Chicago school (Becker (1968), Stigler (1970), Becker and Stigler (1974)). They modeled economic agents as performing a cost-benefit analysis when they breach the law and they reflected on the role of punishments and their limitations due to corruption and limited liability.

In the law and economics literature (Posner (1972), Polinsky (1983)), there has been a lot of work on breach of contracts and on the types of remedies which can be offered by the law. However, the emphasis is there, not on how to react to renegations on contracts in fully anticipated states of nature, but rather on how laws can simply deal with circumstances arising from unexpected states of nature. It is more about how the law can be an efficient substitute to the excessive transaction costs resulting from an attempt to include in contracts all possible contingencies.

The contract literature has developed initially without worrying about the verifiability and contractibility of the actions specified in the contracts. More recently, attention has shifted towards those issues. For example, the income taxation literature has started with Mirrlees (1971) by assuming that incomes are observable. It was only much later (Border and Sobel (1987), Mookherjee and Png (1989), Cremer, Marchand and Pestieau (1990)) that lies of taxpayers about their incomes and the need for auditing incomes were taken into account. Actually, many LDCs are still unable to implement income taxes because of enforcement issues. 
Similarly, the costly state verification literature in loan contracting with asymmetric information (Townsend (1979), Gale and Hellwig (1985)) arose from the difficulties of indexing the repayment of a loan on the firm's revenue, because of this latter's ability to hide its revenue. This transaction cost was used to motivate debt contracts which specify payments unconditional on the firm's revenue.

Also, in the procurement literature the need for auditing costs was taken into account (Baron and Besanko (1984)) with attention given to imperfect commitment of auditing procedures (Khalil (1992)) and to the corruption of auditors (Laffont and Tirole (1992)). In this work, the verification of states of nature is costly, but the enforcement is assumed to be perfect when auditing is successful. Krasa and Villamil (2000) is an exception where costly enforcement is a decision variable and where they show that imperfect commitment makes debt contracts optimal. ${ }^{1}$

In contrast, we assume in this paper that the enforcement of contracts does not solve the asymmetric information problem, but simply forces the regulated firm to select an outcome in the set of allocations agreed upon contractually ex ante. This description of enforcement seems particularly adapted to LDCs and to regulation where solving the asymmetric information problem following a dispute seems much too costly to be realistic and too much opened to manipulation.

In Section 2, we discuss briefly some of the major regulatory issues specific to African economies that are encountered in the current privatization and liberalization movement. Section 3 describes a number of enforcement failures of regulatory contracts in the Telecommunications industry in Africa. Section 4 recaps a basic regulation model inspired from the new regulatory economics. A regulated utility has private information about its cost function and can also decrease cost by an unobservable effort. Cost is ex post observable. The regulatory contract is written before the firm discovers its type (for simplicity, two types only are considered), so that the firm's participation constraint is an ex ante constraint. Consequently, with perfect enforcement of contracts, optimal regulation achieves the full information optimum. However, the ex post utility of an inefficient type is negative. If the regulator cannot enforce such negative utility levels for the firm, it must resort to self-enforcing contracts which ensure ex post non negative levels of utility. Optimal regulation is then identical to the one obtained when the regulator offers a contract after the firm discovers its type. It entails downward distortions of production to achieve the optimal rent extraction-efficiency trade-off. Against these benchmarks we develop in Section 5 a model with imperfect enforcement. The regulator offers a menu of contracts from which the firm must select. With some probability which depends on enforcement expenditures, the firm is indeed forced to choose one contract in the menu.

\footnotetext{
${ }^{1}$ The Townsend-Gale-Hellwig result justifying debt contracts was criticized because they ignored stochastic contracts.
} 
With the complementary probability the contract is renegotiated. Then, we characterize the optimal menu of contracts and the optimal enforcement expenditures. In particular, we find that the optimal level of enforcement decreases with the cost of public funds and with the efficiency of ex post bargaining. In Section 6, we extend the model to account for corruption in the regulatory process and we show that the more prone to corruption the country is the lower the optimal level of enforcement. These results provide some theoretical support to the positive correlation between the level of development and the size of the informal sector (where tax laws are not enforced) largely discussed in development economics. In Section 7, we provide empirical results about a more direct relationship between the level of corruption and the quality of enforcement. We conclude in Section 8.

\section{Regulation in Africa}

In the nineties, largely under the pressure of the IMF and the World Bank, the privatization and liberalization movement has reached Africa and has even concerned the public services such as water, electricity, railways and telecommunications.

Those operations have been conducted sometimes in a hurry (like the privatization of electricity in Côte d'Ivoire), sometimes very slowly (seven years for telecommunications in Côte d'Ivoire), but always within the conceptual framework inherited from the Western World, in the best cases with some knowledge of the Latin America experience.

The specificities of African countries have received little attention, and when they were considered it was very pragmatically. One reason is that there has been very little research in the theory of regulation for developing countries. ${ }^{2}$ Some fundamental questions await theoretical and empirical systematic research. Let us list a few.

Should one pay the social cost of restructuring before privatization to attract capital, or is it better to liquidate bankrupt public firms immediately? Marocco has a systematic approach of privatizing only well restructured and profitable firms. Subsaharan countries often cannot afford financially or politically such restructurations. The privatization of electricity in Côte d'Ivoire was the one of a bankrupt monopoly. Today Côte d'Ivoire exports electricity instead of being an importer before privatization.

Given the high concern for poverty, the fact that public employees often support large families in the country side, what are the optimal downsizing policies associated with restructuring?

The lack of auditing resources constrains a lot the types of regulation mechanisms

\footnotetext{
${ }^{2}$ A few exceptions include Laffont (1996), (1999), Ordover et alii (1994).
} 
(cost of service regulation is only possible if cost is indeed observed). Given the various industries to regulate how should these scarce resources be allocated? More broady how should reform proceed given the resources and political constraints?

What should be the balance between designing a competitive ex post industry structure (which ensures more efficiency ex post, but might discourage ex ante competition) or granting monopoly rights more attractive to investors, but sustaining ex post inefficiencies? How should this balance be affected by the strength and credibility of regulatory institutions? In Telecommunications, Zambia aimed at a very competitive industry and attracted nobody. Côte d'Ivoire was critized for granting a seven years monopoly for fixed link telephony. Ghana issued two licenses of fixed link telephony but the weakness of the regulator did not avoid foreclosure behavior of the incumbent monopolist so that the second operator is not operational.

Given the specificities of African economies concerning the cost of public funds, the auditing resources, the lack of commitment power and of checks and balances, the inefficiencies of capital markets, the weakness of the rule of law, what are the best regulation methods, what is the best rent extraction-efficiency trade-off of incentive regulation?

In particular, LDCs suffer tremendously from a weakness of enforcement capabilities which completely denaturate the regulatory contracts and call for very different choices than those which would be made in countries where reneging on contracts is too costly. Alarmed by the wave of disputes and renegotiations following the huge privatization movement in Latin America, the World Bank has built a data basis to analyze the disturbing fact that concessions are renegotiated after an average of 2.1 years only. All those issues call for specific theoretical and empirical research. However, only a step by step approach seems fruitful from the theoretical point of view.

In the next section we give examples of enforcement failures in the telecommunications industry of Africa to motivate the following sections of this paper which explore how optimal incentive regulation should be affected by enforcement failures.

\section{Enforcement Failures}

\section{- Ghana's Telecommunications}

The targeted design of the Ghanaian Telecommunications industry was unusually competitive for Africa, with three mobile operators and two fixed wire line networks. However, the regulator turned out to be particularly weak and "despite its well-intentioned law, the

weakness of enforcement has left telecommunication consumers at the mercy of a battle of influence between the champions of the various players. One serious casualty may be 
Ghana's credibility with investors" Haggarty and Shirley (1999).

A spectacular example of lack of enforcement is the fact that the incumbent monopoly for fixed telephony ${ }^{3}$ GT who was not allowed to enter the mobile business did enter, and furthermore used all kinds of tactics to delay interconnection. ${ }^{4}$ Furthermore, interconnection disputes with GT have also prevented the second fixed link operator from entering until recently.

\section{- Tanzania's Telecommunications}

In Tanzania the regulator attempted to enforce regional mobile licenses. However, the dominant mobile operator Mobitel argued that its license was national, and launched service in an area where the regulator tried to shut down the operator. After a crisis involving the court and the President of the country all cellular licenses were declared national in scope.

At the opposite governments and regulators also break contracts. In Tanzania the initial two cellular operators complained that the Government commitments to having only two or three operators in the market was reneged on with impunity. ${ }^{5}$

\section{- Côte d'Ivoire's Telecommunications}

The concession contract of CItelecom specified quality levels and an expansion program of fixed lines which repeatedly have not been satisfied. Despite the existence of penalties in the contract, the regulator has not exercised these penalties and has not succeeded in implementing the contract.

CItelecom has priced access for public phones built by the competitor Publicom at a price of 65 FCFA per impulse, while the price in its own public phones was 73 . The margin of 8 FCFA was to small to allow entry. In August 1998 the regulator intervened to set a minimum price of 85 FCFA for CItelecom's own call boxes. However, CItelecom refused $^{6}$ to adjust its prices until very recently and since then imposes long delays for connecting competitors' call boxes.

More generally, the size of the informal economy can be viewed as a measure for the weakness of law enforcement. It is by now well established that the size of the shadow economy as a percentage of GDP is larger in developing than developed countries (see Schneider and Enste (2000)) and that there is a positive correlation between the size of

\footnotetext{
${ }^{3}$ It was bought by Telekom Malaysia through a competitive tender.

${ }^{4} \mathrm{GT}$ has been charging cellular companies more that its local retail tariff.

${ }^{5}$ We will not develop this dimension of renegotiation. See Aubert and Laffont (2001) for a model of political renegotiation.

${ }^{6}$ The reason put forward by CItelecom to justify their behavior is that they consider that public phones belong to the fixed network and therefore fall into their monopoly license.
} 
the informal economy and higher corruption. Johnson et alii (1998) finds that a one point improvement in the corruption index (using either the Transparency International measure of corruption or the Global Competitiveness Survey measure of bribery) is associated with around a 4 percentage point fall in the share of the informal economy, after controlling for per capita income.

\section{Optimal Regulation}

We consider a natural monopoly which, in addition to a fixed cost $F$ which is common knowledge has a variable cost function:

$$
C=(\beta-e) q,
$$

where $q$ is the production level, $\beta$ is an adverse selection parameter in $\{\underline{\beta}, \bar{\beta}\}$ with $\nu=$ $\operatorname{Pr}(\beta=\underline{\beta})$ and $e$ is a moral hazard variable which decreases cost, but creates to the manager a disutility $\psi(e)$ with $\psi^{\prime}(\cdot)>0, \psi^{\prime \prime}>0, \psi^{\prime \prime \prime} \geq 0$.

Consumers derive an utility $S(q), S^{\prime}>0, S^{\prime \prime}<0$ from the consumption of the natural monopoly's good. Let $p(\cdot)$ the inverse demand function and $\hat{t}$ the transfer to the firm from the regulator. The firm's net utility writes:

$$
U=\hat{t}+p(q) q-(\beta-e) q-F-\psi(e) .
$$

We assume that cost is ex post observable by the regulator as well as the price and the quantity. So, we can make the accounting assumption that revenues and cost are incurred by the regulator, who pays a net transfer $t=\hat{t}+p(q) q-(\beta-e) q-F$. Accordingly, the participation constraint of the firm can be written:

$$
U=t-\psi(e) \geq 0 \text {. }
$$

To finance the transfer $t$, the government must raise taxes with a cost of public funds $1+\lambda, \lambda>0$. Hence, consumers' net utility is

$$
V=S(q)-p(q) q-(1+\lambda) t
$$

Utilitarian social welfare writes then:

$$
W=U+V=S(q)+\lambda p(q) q-(1+\lambda)((\beta-e) q+F+\psi(e))-\lambda U .
$$

Under complete information, the maximization of social welfare would lead to:

$$
\begin{aligned}
S^{\prime}\left(q^{*}\right)+\lambda\left(p^{\prime}\left(q^{*}\right) q^{*}+p\left(q^{*}\right)\right) & =(1+\lambda)\left(\beta-e^{*}\right) \\
\psi^{\prime}\left(e^{*}\right) & =q^{*} \\
U & =0 .
\end{aligned}
$$


Let us denote, for $\underline{\beta}$ and $\bar{\beta}$ respectively, the solutions of $(4.6),(4.7),(4.8)^{7}$ as $\underline{q}^{*}, \underline{e}^{*}, \underline{U}^{*}$ and $\bar{q}^{*}, \bar{e}^{*}, \bar{U}^{*}$.

Since consumers equate their marginal utility to the price $\left(S^{\prime}(q)=p\right),(4.8)$, which says that social marginal utility equals social marginal cost, can be rewritten as a Lerner index formula:

$$
\frac{p-(\beta-e)}{p}=\frac{\lambda}{1+\lambda} \frac{1}{\eta(p)},
$$

where $\eta(p)$ is the price elasticity of demand. The price is between the marginal cost $(\beta-e)$ and the monopoly price $p^{M}$ defined by

$$
\left(\frac{p^{M}-(\beta-e)}{p^{M}}=\frac{1}{\eta(p)}\right) .
$$

The marginal disutility of effort $\psi^{\prime}(e)$ is equated to its marginal social gain $q$, and no rent is given up to the firm because funds are socially costly $(\lambda>0)$.

Suppose now that the regulator cannot observe the effort level $e$ and does not know $\beta$. However, he can offer a contract to the firm before the latter discovers its type (see Figure 1 for the timing).

\begin{tabular}{ccccc}
\hline $\begin{array}{c}\text { The regulator } \\
\text { offers }\end{array}$ & $\begin{array}{c}\text { The firm } \\
\text { accepts or not }\end{array}$ & The firms & Production & Time \\
the regulatory & the contract & its & and & \\
contract & & type $\beta$ & transfer &
\end{tabular}

\section{Figure 1}

In addition to the participation constraint, the regulator's contract must now satisfy the firm's incentive constraints because of incomplete information. The firm's utility level can be rewritten by substitution of (4.1) in (4.3):

$$
U=t-\psi(\beta-c)
$$

where $c=\frac{C}{q}$ is average cost. (4.9) shows that the observability of cost reduces the problem to a simple adverse selection problem. From the Revelation Principle, there is no loss of generality in restricting the analysis to direct revelation mechanisms $\{(\underline{t}, \underline{c}),(\bar{t}, \bar{c})\}$ which specify for each message $\tilde{\beta}=\underline{\beta}$ or $\tilde{\beta}=\bar{\beta}$ an average cost to achieve and a net transfer from the regulator.

\footnotetext{
${ }^{7}$ We make the appropriate assumptions on $S(\cdot)$ so that $W$ is strictly concave in $(q, e)$. For more details and motivations about the various assumptions see Laffont and Tirole (1993).
} 
The regulatory contract also recommends a production level $\underline{q}$ (or $\bar{q}$ ) and a total cost $\underline{C}$ (or $\bar{C}$ ), compatible with $\underline{c}$ (or $\bar{c}$ ) (between which the firm is indifferent) which maximize expected social welfare.

However, the direct revelation mechanism must be truthful, i.e., must satisfy the incentive constraints

$$
\begin{aligned}
\underline{U} & =\underline{t}-\psi(\underline{\beta}-\underline{c}) \geq \bar{t}-\psi(\underline{\beta}-\bar{c}) \\
\bar{U} & =\bar{t}-\psi(\bar{\beta}-\bar{c}) \geq \underline{t}-\psi(\bar{\beta}-\underline{c}) .
\end{aligned}
$$

Since the firm must accept or reject the contract before it knows its type, its participation constraint must be written ex ante, i.e.:

$$
\nu \underline{U}+(1-\nu) \bar{U} \geq 0
$$

The incentive constraints (4.10) (4.11) can be rewritten:

$$
\begin{aligned}
& \underline{U} \geq \bar{U}+\Phi(\bar{e}) \\
& \bar{U} \geq \underline{U}-\Phi(\underline{e}+\Delta \beta),
\end{aligned}
$$

where $\Phi(e)=\psi(e)-\psi(e-\Delta \beta), \Phi^{\prime}>0, \Phi^{\prime \prime}>0$.

Finally, the regulator's maximization program writes: $(P):$

$$
\begin{aligned}
& \max \nu[S(\underline{q})+\lambda p(\underline{q}) \underline{q}-(1+\lambda)(\underline{c} \underline{q}+\psi(\underline{\beta}-\underline{c}))-\lambda \underline{U}] \\
& +(1-\nu)[S(\bar{q})+\lambda p(\bar{q}) \bar{q}-(1+\lambda)(\bar{c} \bar{q}+\psi(\bar{\beta}-\bar{c}))-\lambda \bar{U}],
\end{aligned}
$$

s.t. (4.10) (4.11) (4.12).

It is more transparent to rewrite this program in terms of the variables $(q, e, U)$ rather than $(q, c, U)$. Let us also denote $W(q, e, \beta)$ the complete information ex post social welfare for a production level $q$ and an effort level $e$ when the efficiency parameter is $\beta$, i.e.:

$$
W(q, e, \beta)=S(q)+\lambda p(q) q-(1+\lambda)((\beta-e) q+F+\psi(e)) .
$$

The regulator's program rewrites:

$$
\max \nu[W(\underline{q}, \underline{e}, \underline{\beta})-\lambda \underline{U}]+(1-\nu)[W(\bar{q}, \bar{e}, \bar{\beta})-\lambda \bar{U}]
$$

s.t.

$$
\begin{aligned}
\underline{U} & \geq \bar{U}+\Phi(\bar{e}) \\
\bar{U} & \geq \underline{U}-\Phi(\underline{e}+\Delta \beta) \\
\nu \underline{U}+(1-\nu) \bar{U} & \geq 0,
\end{aligned}
$$


Actually, the regulator can saturate the participation constraint and maximize social welfare. For each value of $\beta$ he finds the complete information optimum. It remains to check if one can find values of rents (or net transfers) such that (4.16) and (4.17) are satisfied. There are many such transfers. If we saturate (4.16) we get:

$$
\bar{U}=-\nu \Phi(\bar{e})
$$

or

$$
\bar{t}=\psi(\bar{e})-\nu \Phi(\bar{e})
$$

If we saturate (4.17), we get instead:

$$
\bar{U}=-\nu \Phi(\underline{e}+\Delta \beta)
$$

or

$$
\bar{t}=\psi(\bar{e})-\nu \Phi(\underline{e}+\Delta \beta) .
$$

Any value of $\bar{t}$ between those obtained in (4.20) and (4.21) would work. Adding (4.16) and (4.17) we obtain:

$$
\Phi(\underline{e}+\Delta \beta) \geq \Phi(\bar{e}) .
$$

The main point to notice is that the inefficient type $\bar{\beta}$ 's ex post utility is always negative and, from (4.22), the largest ex post utility is obtained when we saturate (4.13).

This negative ex post utility raises the issue of enforcement. Indeed, once it discovers its type $\bar{\beta}$ the firm would like to renege on the regulatory contract. In a country with strong institutions, the contract is enforced in both states of nature $\underline{\beta}$ and $\bar{\beta}$. As a consequence, asymmetric information does not create any transaction cost for society and the complete information optimal allocation is achieved despite the setting of incomplete information.

At the other extreme, suppose that the regulator anticipates that he will not be able to enforce a negative ex post utility level for the firm. Then, he will chose a regulatory contract which maximizes expected social welfare under the incentive constraints, but also the ex post participation constraints:

$$
\begin{aligned}
& \underline{U} \geq 0 \\
& \bar{U} \geq 0 .
\end{aligned}
$$

The set of constraints is then the same as if the contract was offered to the firm at the interim stage, i.e., once it knows its type. Then, we can anticipate that the efficient 
type's incentive constraint (4.16) and the inefficient type's participation constraint (4.24) will be the binding ones. Substituting into the objective function of the regulator, we obtain:

$$
\begin{aligned}
\psi^{\prime}\left(\bar{e}^{S B}\right) & =\bar{q}^{S B}-\frac{\lambda}{1+\lambda} \cdot \frac{\nu}{1-\nu} \Phi^{\prime}\left(\bar{e}^{S B}\right) \\
\psi^{\prime}\left(\underline{e}^{S B}\right) & =\underline{q}^{S B}=\underline{q}^{*} \\
\underline{U} & =\Phi\left(\bar{e}^{S B}\right)>0,
\end{aligned}
$$

and the same pricing equations as under complete information. ${ }^{8}$

Now, the efficient type captures a positive rent, and to decrease somewhat this socially costly rent the regulator decreases the effort level in the case $\beta=\bar{\beta}$. However, the efficient type's effort level is not distorted.

Then, the loss in expected social welfare due to the extreme weakness of enforcement institutions and the need to rely on self-enforcing contracts writes:

$$
\Delta W^{S B}=\underbrace{\lambda \nu \Phi\left(\bar{e}^{S B}\right)}_{\text {Rent Loss }}+(1-\nu) \underbrace{\left[W\left(\bar{q}^{*}, \bar{e}^{*}, \bar{\beta}\right)-W\left(\bar{q}^{S B}, \bar{e}^{S B}, \bar{\beta}\right)\right]}_{\text {Efficiency Loss }} .
$$

\section{Regulation and Enforcement}

We want to model now more precisely what happens when institutions ensure only an imperfect enforcement of regulatory contracts.

We will assume that when the firm obtains an ex post negative utility, it attempts to renegotiate its regulatory contract. However, with a probability $\pi(c)$, the regulator is able nevertheless to impose the implementation of the agreed upon contract. ${ }^{9}$ This probability depends on the expenses $c$ incurred to set up an efficient enforcement mechanism: We assume that $\pi(0)=0, \pi^{\prime}>0, \pi^{\prime \prime}<0$ with the Inada conditions $\pi^{\prime}(0)=\infty$ and $\lim _{c \rightarrow \infty} \pi(c)=1$.

With probability $1-\pi(c)$ the regulator is forced to accept a renegotiation. To model this renegotiation we use the Nash bargaining solution but assume that renegotiation is costly (become it takes time say). The status quo payoffs which obtain if the negotiation

\footnotetext{
${ }^{8}$ This is due to the fact that the cost function we have chosen satisfies the separability assumption $C(q, h(\beta, e))$ which implies the dichotomy property, i.e., the absence of incentive correction in the pricing formula (see Laffont and Tirole (1993)).

${ }^{9}$ We do not allow for penalties when enforcement is successful. This seems more descriptive of real practice in regulation (limited penalties would not change the flavor of the results), probably because often regulatory agencies are not allowed to impose penalties and do not want to go to court if they manage to enforce the contract. When enforcement is not successful, costly renegotiation is ex post better than enforcing penalties.
} 
fails are determined as follows: The firm loses its fixed cost and gets the utility level $U_{0}=-F$. The regulator is also penalized by a loss of reputation and obtains the utility level $W_{0}=-H$.

We will make appropriate assumptions so that the efficient type firm never wants to renege on its contract. ${ }^{10}$ Therefore, costly bargaining takes place under complete information, only when $\beta=\bar{\beta}$. Its outcome solves:

$$
\max _{\{\bar{q}, \bar{e}, \bar{U}}\left\{\left(\bar{U}^{E}-U_{0}\right)\left(\delta W(\bar{q}, \bar{e}, \bar{\beta})-\lambda \bar{U}^{E}-W_{0}\right)=\left(\bar{U}^{E}+F\right)\left(\delta W(\bar{q}, \bar{e}, \bar{\beta})-\lambda \bar{U}^{E}+H\right)\right\}
$$

with $\delta$ in $(0,1)$ to model the cost of renegotiation.

It yields the complete information production and effort levels $\bar{q}^{*}, \bar{e}^{*}$ and the rent level

$$
\bar{U}^{E}=\frac{\delta W\left(\bar{q}^{*}, \bar{e}^{*}, \bar{\beta}\right)+H}{2 \lambda}-\frac{F}{2},
$$

i.e., the firm and the regulator share equally the social surplus. Social welfare is then

$$
\bar{W}^{E}=\frac{\delta W\left(\bar{q}^{*}, \bar{e}^{*}, \bar{\beta}\right)-H+\lambda F}{2} .
$$

The higher the fixed cost, the lower the firm's rent from renegotiation and the higher social welfare will be despite renegotiation. The weaker the regulator position in case of unsuccessful renegotiation (the higher $H$ ), the lower is social welfare.

We still need the offer of contracts to be incentive compatible (conditions (4.16), (4.17)) and the new ex ante participation constraint writes

$$
\nu \underline{U}+(1-\nu) \pi(c) \bar{U}+(1-\nu)(1-\pi(c)) \bar{U}^{E} \geq 0 .
$$

Substituting the outcome of renegotiation into the regulator's objective function, it becomes

$$
\begin{aligned}
& \nu[W(\underline{q}, \underline{e}, \underline{\beta})-\lambda \underline{U}]+(1-\nu) \pi(c)[W(\bar{q}, \bar{e}, \bar{\beta})-\lambda \bar{U}] \\
& \quad+(1-\nu)(1-\pi(c))\left[\delta W\left(\bar{q}^{*}, \bar{e}^{*}, \bar{\beta}\right)-\lambda \bar{U}^{E}\right]-(1+\lambda) c .
\end{aligned}
$$

Maximizing by saturating the participation constraint we obtain:

$$
\begin{aligned}
\underline{q}^{E} & =\underline{q}^{*} ; \quad \underline{e}^{E}=\underline{e}^{*} \\
\bar{q}^{E} & =\bar{q}^{*} ; \quad \bar{e}^{E}=\bar{e}^{*} \\
(1-\nu) \pi^{\prime}\left(c^{E}\right) & =\frac{1+\lambda}{(1-\delta) W\left(\bar{q}^{*}, \bar{e}^{*}, \bar{\beta}\right)} .
\end{aligned}
$$

\footnotetext{
${ }^{10}$ See Appendix 1. From Bester and Strausz (2000) we can restrict the analysis to pairs of contracts.
} 
Clearly, it is valuable to build an enforcement institution only when the social welfare obtained by the initial contract for $\beta=\bar{\beta}$ is higher than what would result from renegotiation $\left(W\left(\bar{q}^{*}, \bar{e}^{*}, \bar{\beta}\right)>\delta W\left(\bar{q}^{*}, \bar{e}^{*}, \bar{\beta}\right)\right)$. The more efficient is renegotiation ( $\delta$ higher), the smaller $c^{E}$. More efficient renegotiation and more enforcement are substitute instruments. $^{11}$

What are the main features of the solution obtained above? First, an enforcement mechanism is financed. It is imperfect and its quality is determined by (5.7). The quality of enforcement decreases (and therefore the probability of renegotiation increases) with the cost of public funds and with the efficiency of ex post bargaining. Second, the power of incentives is not intermediary between those which will be obtained with perfect enforcement (high powered) and self-enforcing contracts (low powered). This is because any rent obtained ex post through renegotiation is captured ex ante in the contract offered by the government. Third, the status quo payoffs of the two players who bargain do not affect the outcome, because again the rent given up in the bargaining is recaptured ex ante as bargaining is anticipated. If these payoffs affected the efficiency $(\delta)$ of bargaining, of course, they would matter.

Note that, if bargaining was efficient, then the analog of (5.7) would imply that $c^{E}=0$. But, then the efficient type would want to mimic the inefficient type because he would get a rent of $\Phi\left(\bar{e}^{*}\right)$ rather than $\Phi(\bar{e}) .{ }^{12}$ Bargaining would then occur ex post for all types under incomplete information, and the only thing the regulator would have gain by not offering a self enforcing contract would be eventually to lose the bargaining power he had ex ante. Indeed, the welfare of the self enforcing contract is the best he could obtain ex post if he had all the bargaining power. ${ }^{13}$

Remark: Another interpretation of $\delta$ (which should then affect also $\bar{U}^{E}$ ) could be some ability of the regulator to commit not to renegotiate. As an extreme case, the regulator might be able to end the relationship if the enforcement mechanism is not successful. Then (5.7) is replaced by

$$
(1-\nu) \pi^{\prime}\left(c^{E}\right)=\frac{1+\lambda}{W\left(\bar{q}^{*}, \bar{e}^{*}, \bar{\beta}\right)+H+F} .
$$

The more the regulator would suffer from the failure to enforce the contract ( $H$ high) and the higher the lost fixed cost $F$, the higher the investment in enforcement.

However, if the enforcement mechanism is not very efficient, it could be that (due to

\footnotetext{
${ }^{11}$ This is true locally, i.e., as long as the efficient type's incentive constraint is not binding.

${ }^{12}$ This is true as long as the inefficient type wants to renegotiate. However, if the sunk cost is very large, then $\bar{U}^{E}<0$ and the inefficient type does not want to renege despite the fact that the contract is never enforced because he loses too much in the renegotiation.

${ }^{13}$ The same reasoning would apply to semi-separating equilibria in which efficient firms mimic inefficient ones only with some probability.
} 
the loss of trade when enforcement fails) the optimal solution obtained above is dominated by self-enforcing contracts.

Indeed, the welfare loss with respect to the first best writes now:

$$
\begin{aligned}
\Delta W^{E} & =(1-\nu)\left(1-\pi\left(c^{E}\right)\right)(1-\delta) W\left(\bar{q}^{*}, \bar{e}^{*}, \bar{\beta}\right) & & \text { Bargaining Costs } \\
& +(1+\lambda) c^{E} & & \text { Enforcement Costs. }
\end{aligned}
$$

However, it may be a little misleading to include in the welfare loss the enforcement costs, since it suggests that the enforcement institutions which yield the first-best in developed countries are costless. Actually, they are not really comparable. In some sense they have been partly sunk in the past so that they are relatively small in comparison with the enforcement needed today in a developing country to eradicate opportunistic behavior.

Still, $\Delta W^{E}$ is the right expression to compare to $\Delta W^{S E}$ obtained in (4.28) to know if it is worth setting up an (imperfect) enforcement institution rather than relying only on self-enforcing contracts.

\section{Enforcement and Corruption}

Let us extend the basic model with a regulatory body which helps the government to bridge partially its information gap with the regulated firm.

The regulator observes a signal $\sigma$ in $\{\phi, \underline{\beta}\}$. More specifically, with probability $\xi$ the regulator observes $\sigma=\underline{\beta}$ when indeed $\beta=\underline{\beta}$ and nothing otherwise. Furthermore, $\sigma=\underline{\beta}$ is a hard information signal which is therefore contractible.

The regulator's utility function is $V(s)=s \geq 0$, where $s$ is his payment from the government.

Suppose first that the regulator is benevolent. Then, with probability $\nu \xi$, the government is informed that the firm is a $\beta$-firm and can achieve the optimal complete information regulation characterized by (4.6), (4.7), (4.8).

If $\sigma=\phi$, the government computes its posterior beliefs $\hat{\nu}=\frac{\nu(1-\xi)}{1-\nu \xi}$ and the optimal regulation under incomplete information and imperfect enforcement characterized in (5.5) to (5.7) where $\hat{\nu}$ replaces $\nu$.

If the regulator is not benevolent, it means that it must be rewarded when he transmits the verifiable signal $\sigma=\underline{\beta}$ to avoid collusion with the agent. Indeed, if the $\underline{\beta}$-firm convinces the regulator to claim that, contrary to the truth, it has observed nothing, it captures the 
rent $\Phi\left(\bar{e}^{C}\right)$.

The collusion-proof constraint writes $\underline{s} \geq k \Phi\left(\bar{e}^{C}\right)$ with $k$ in $(0,1)$. Collusion proofness ${ }^{14}$ entails consequently an additional expected social cost $\lambda \nu \xi k \Phi\left(\bar{e}^{C}\right)$ in the government's objective function (5.4) which becomes:

$$
\begin{aligned}
& \nu \xi W\left(\underline{q}^{*}, \underline{e}^{*}, \underline{\beta}\right)+\nu(1-\xi)[W(\underline{q}, \underline{e}, \underline{\beta})-\lambda \underline{U}] \\
& \quad+(1-\nu) \pi(c)[W(\bar{q}, \bar{e}, \bar{\beta})-\lambda \bar{U}]+(1-\nu)(1-\pi(c))\left[\delta W\left(\bar{q}^{*}, \bar{e}^{*}, \bar{\beta}\right)-\lambda \bar{U}^{C}\right] \\
& \quad-(1+\lambda) c-\lambda \nu \xi k \Phi\left(\bar{e}^{C}\right) .
\end{aligned}
$$

Hence, the first-order conditions:

$$
\begin{aligned}
\underline{q}^{C} & =\underline{q}^{*} ; \quad \underline{e}^{C}=\underline{e}^{*} \\
\psi^{\prime}\left(\bar{e}^{C}\right) & =\bar{q}^{C}-\frac{\lambda}{1+\lambda} \cdot \frac{\nu k \xi}{1-\nu} \frac{\Phi\left(\bar{e}^{C}\right)}{\pi\left(c^{C}\right)} \\
S^{\prime}\left(\bar{q}^{C}\right)+\lambda\left[p^{\prime}\left(\bar{q}^{C}\right) \bar{q}^{C}+p\left(\bar{q}^{C}\right)\right] & =(1+\lambda)\left(\bar{\beta}-\bar{e}^{C}\right) \\
(1-\nu) \pi^{\prime}\left(c^{C}\right) & =\frac{1+\lambda}{W\left(\bar{q}^{C}, \bar{e}^{C}, \bar{\beta}\right)-\delta W\left(\bar{q}^{*}, \bar{e}^{*}, \bar{\beta}\right)} .
\end{aligned}
$$

The comparative statics analysis of this system yields immediately (see Appendix 2).

\section{Proposition 1 :}

$$
\frac{d c^{C}}{d k}<0 \quad \frac{d \bar{q}^{C}}{d k}<0 \quad \frac{d \bar{e}^{C}}{d k}<0
$$

In a country prone to corruption ( $k$ high), optimal regulation leads to less high powered incentive schemes (because informational rents are more costly), to less production and higher prices (because costs are higher due to lower effort levels induced by low powered incentive schemes), and more importantly for our analysis here, to less enforcement. Indeed, enforcement is less valuable (because of the distortions described above).

We recalled in Section 3 that there is a well established negative correlation between the quality of law enforcement and the level of development or the level of corruption. The above result shows that low enforcement is in fact an optimal regulatory response to the proneness to corruption and not necessarily an institutional weakness in itself.

The welfare loss due to asymmetric information and enforcement costs is now

\footnotetext{
${ }^{14}$ See Laffont and Tirole (1993).
} 


$$
\begin{aligned}
& \Delta W^{C}=(1-\nu) \pi\left(c^{C}\right)\left[W\left(\bar{q}^{*}, \bar{e}^{*}, \bar{\beta}\right)-W\left(\bar{q}^{C}, \bar{e}^{C}, \bar{\beta}\right)\right] \quad \text { Efficiency loss due to the Rent Extraction } \\
& \text { - Efficiency Trade-Off. } \\
& +(1-\nu)\left(1-\pi\left(c^{C}\right)\right)(1-\delta) W\left(\bar{q}^{*}, \bar{e}^{*}, \beta\right) \quad \text { Bargaining Costs. } \\
& +(1+\lambda) c^{C} \quad \text { Enforcement Costs. } \\
& +\lambda \nu \xi k \Phi\left(\bar{e}^{C}\right) \quad \text { Incentive Costs of Regulators. }
\end{aligned}
$$

Finally, note also the possible countervailing effect. The optimal enforcement level decreases with $\xi$. A less efficient regulation associated with a LDC, in the sense of a lower value of $\xi$, leads to more enforcement because it decreases the cost of collusionproofness hence increases efficiency, hence increases the gain from enforcement. A More direct link that the direct link which would arise from a corruption of the enforcement system itself. For example if $\pi(\cdot)=\theta \pi(\cdot), \theta$ appears as a measure of lack of corruption in the enforcement system and indeed we obtain directly $\frac{d c^{C}}{d \theta}>0$.

Data about the enforcement of regulation or the probability of renegotiation allowing an econometric study are not yet available for Africa. In the next section we investigate the correlation between corruption and the quality of enforcement on more general data sets and point out an Africa effect.

\section{Empirical Correlation between Corruption and the Enforcement of Contracts}

For the corruption variable we use two measures ${ }^{15}$ denoted KAUFCOR from Kaufman et alii (1999) and TICORR98 for transparency international. For the quality of enforcement we use either the rule of law variable (KAUFRUL) from Kaufman et alii (1999) or the law and order variable (PRSLOR) from PRS-ICRG. Using two stage least squares with the instruments (IMPGDP for openess = Imports / GDP from the WBDR and PRICDIST as the index of price distortions (for Freedom House)). One can expect these variables associated with rents which can be captured to be correlated with corruption and not (at least much less) with the rule of law. We also introduce a dummy variable for the countries of Sub-Sahara Africa. We obtain Tables 1, 2, 3.

\footnotetext{
${ }^{15}$ See Appendix 3 for more details on data.
} 
Table 1

Endogenous Variable KAUFRUL

\begin{tabular}{|l|c|c|c|c|c|}
\hline & LS & TSLQ & TSLQ & TSLS & TSLS \\
\hline C & 0.89 & 0.60 & -2.25 & -2.07 & -2.19 \\
& $(1.84)$ & $(0.47)$ & $(-1.29)$ & $(-1.18)$ & $(-1.21)$ \\
& & & & & \\
& -0.04 & -0.03 & 0.06 & 0.06 & 0.06 \\
TICORP98 & $(-2.70)$ & $(-0.91)$ & $(1.16)$ & $(1.08)$ & $(1.10)$ \\
& & & & & \\
KAUFCOR & 0.66 & 0.71 & & & \\
& $(9.68)$ & $(3.80)$ & & & \\
SSA & & & & & \\
& & & $(4.54)$ & $(4.22)$ & $(4.20)$ \\
\hline$R^{2}$ & & & & & \\
SE & & & & 0.25 & 0.06 \\
$\mathrm{~N}$ & 0.83 & 0.83 & 0.70 & 0.75 & 0.74 \\
\hline
\end{tabular}

The corruption variables are significant even after being instrumented. Furthermore a Hausman test shows that TICORR98 can be considered as exogenous (but not KAURCOR). 
Table 2

Endogenous Variable PRSLOR 98

\begin{tabular}{|l|c|c|c|c|}
\hline & LS & TSLS & TSLS & TLSL \\
\hline C & 0.91 & 1.58 & 0.36 & 1.59 \\
& $(0.95)$ & $(0.84)$ & $(0.12)$ & $(0.54)$ \\
GNP98 & -0.06 & -0.07 & -0.03 & -0.07 \\
& $(-1.96)$ & $(1.47)$ & $(-0.39)$ & $(-0.75)$ \\
TICORR98 & 0.55 & 0.46 & & \\
& $(4.11)$ & $(1.77)$ & & \\
KAUFCOR & & & 0.69 & 0.45 \\
& & & $(1.64)$ & $(1.02)$ \\
SSA & & & & \\
& & & & 1.21 \\
$R^{2}$ & 0.54 & 0.55 & 0.57 & 0.59 \\
SE & 1.77 & 1.77 & 1.84 & 1.80 \\
$\mathrm{~N}$ & 76 & 74 & 92 & 92 \\
\hline
\end{tabular}

The corruption variables are less significant with PRSLOR98 as an endogenous variable. The SSA dummy is more significant.

Table 3 (only SSA)

\begin{tabular}{|l|c|}
\hline & $\begin{array}{c}\text { Endogenous Variable KAUFRUL } \\
\text { (SSA) }\end{array}$ \\
\hline & TSLS \\
\hline C & -4.15 \\
& $(-0.80)$ \\
\hline GNP 98 & -0.03 \\
& $(-0.05)$ \\
\hline KAUFCOR & 1.46 \\
& $(2.11)$ \\
\hline$R^{2}$ & 0.13 \\
SE & 1.77 \\
N & 26 \\
\hline
\end{tabular}

The instrumented corruption variable is significant. 


\section{Concluding Comments}

The purpose of this paper was to develop a regulation model integrating two main features of LDCs, namely the lack of information suffered by regulators and the weakness of enforcement institutions. In particular, we found that the proneness to corruption favors low powered incentives schemes and low levels of enforcement expenditures. We have documented empirically the positive correlation between the level of corruption and the quality of enforcement, and we have identified a weak Africa effect which worsens the quality of enforcement for given GNP and corruption levels. As usual the difficulty of finding satisfactory instruments makes us very prudent in the interpretation of these empirical results. However, this paper points towards an interesting relation between the characteristics of an economy favoring corruption and the endogenous quality level of desirable enforcement. We hope to document this relationship on micro data sets in the future. 


\section{Appendix 1}

We want to show under which circumstances, when the solution characterized by $(5.5)$ (5.6) (5.7) dominates for the regulator the optimal self-enforcing contracts, it is indeed the case that the efficient type does not want to renege on the contract.

With the initial contract, the $\beta$-firm obtains the utility $\Phi\left(\bar{e}^{E}\right)$. If the $\beta$-firm tries to

renegotiate, with probability $1-\pi\left(c^{E}\right)$ the regulator who believes that he is facing an inefficient firm (remember that we are out of equilibrium) will offer a contract yielding $\bar{U}^{E}+\Phi\left(\bar{e}^{*}\right)$.

So, we need

$$
\bar{U}^{E} \leq \Phi\left(\bar{e}^{E}\right)-\Phi\left(e^{*}\right)
$$

or

$$
\delta \leq \lambda F-H 2 \lambda\left(\Phi\left(\bar{e}^{*}\right)-\Phi\left(\bar{e}^{E}\right)\right)
$$

i.e., enough inefficiency in bargaining or $F$ large enough. 


\section{Appendix 2}

The new participation constraint is:

$$
\nu(1-\xi) \underline{U}+(1-\nu) \pi(c) \bar{U}+(1-\nu)(1-\pi(c)) \bar{U}^{B}=0 .
$$

Substituting into the government's objective function we get:

$$
\begin{aligned}
\nu W\left(\underline{q}^{*}, \underline{e}^{*}, \underline{\beta}\right)+\nu(1-\xi) W(\underline{q}, \underline{e}, \underline{\beta}+(1-\nu) \pi(c) W(\bar{q}, \bar{e}, \bar{\beta}) \\
\quad+(1-\nu)(1-\pi(c)) \delta W\left(\bar{q}^{*}, \bar{e}^{*}, \bar{\beta}\right)-(1+\lambda) c-\lambda \nu \xi k \Phi(\bar{e}) .
\end{aligned}
$$

Maximizing with respect to $\underline{e}, \underline{q}, \bar{e}, \bar{q}, c$ we obtain

$$
\begin{gathered}
\underline{q}^{C}=\underline{q}^{*} \quad ; \quad \underline{e}^{C}=\underline{e}^{*} \\
-\left(\psi^{\prime}\left(\bar{e}^{C}\right)-\bar{q}^{C}\right)(1+\lambda)(1-\nu) \pi(\bar{c})-\lambda \nu \xi k \Phi^{\prime}(\bar{e})=0 \\
S^{\prime}\left(\bar{q}^{C}\right)+\lambda\left[p^{\prime}\left(\bar{q}^{C}\right) \bar{q}^{c}+p\left(\bar{q}^{C}\right)\right]-(1+\lambda)\left(\bar{\beta}-\bar{e}^{C}\right)=0 \\
(1-\nu) \pi^{\prime}\left(c^{C}\right)\left[W\left(\bar{q}^{C}, \bar{e}^{C}, \bar{\beta}\right)-\delta W\left(\bar{q}^{*}, \bar{e}^{*}, \bar{\beta}\right)\right]-(1+\lambda)=0 .
\end{gathered}
$$

Differentiating we obtain:

$$
\begin{aligned}
& {\left[\begin{array}{lll}
-\psi^{\prime \prime}(1+\lambda)(1-\nu) \pi(\bar{c})-\lambda \nu \xi k \Phi^{\prime \prime} & (1+\lambda)(1-\nu) \pi(\bar{c}) & -\left(\psi^{\prime}-\bar{q}\right)(1+\lambda)(1-\nu) \pi^{\prime} \\
(1+\lambda) & S^{\prime \prime}+\lambda\left[p^{\prime \prime} q+2 p^{\prime}\right] & 0 \\
(1-\nu) \pi^{\prime}\left(c^{C}\right) W_{e}\left(\bar{q}^{C}, \bar{e}^{C}, \bar{\beta}\right) & (1-\nu) \pi^{\prime}\left(c^{C}\right) W_{q}\left(\bar{q}^{C}, \bar{e}^{C}, \bar{\beta}\right) & (1-\nu) \pi^{\prime \prime}\left(W\left(\bar{q}^{C}, \bar{e}^{C}, \bar{\beta}\right)-\delta W\left(\bar{q}^{*}, \bar{e}^{*}, \bar{\beta}\right)\right)
\end{array}\right]} \\
& \\
& {\left[\begin{array}{c}
d \bar{e}^{C} \\
d \bar{q}^{C} \\
d c^{C}
\end{array}\right]=\left[\begin{array}{c}
\lambda \nu \xi \Phi^{\prime} \\
0 \\
0
\end{array}\right] d k}
\end{aligned}
$$

From the concavity of the objective function at the optimum, the Jacobian is negative.

$$
\begin{aligned}
& \frac{d \bar{e}^{C}}{d k}=-\left|\begin{array}{ccc}
+ & + & - \\
0 & - & 0 \\
0 & + & -
\end{array}\right|<0 \\
& \frac{d \bar{q}^{C}}{d k}=-\left|\begin{array}{ccc}
- & + & - \\
+ & 0 & 0 \\
+ & 0 & -
\end{array}\right|<0 \\
& \frac{d \bar{c}^{C}}{d k}=-\left|\begin{array}{ccc}
- & + & + \\
+ & - & 0 \\
+ & + & 0
\end{array}\right|<0 .
\end{aligned}
$$

Similarly we find

$$
\frac{d c^{C}}{d \xi}<0
$$

Suppose that $\theta \pi(c)$ and that $\theta$ is an index of lack of corruption in the enforcement system. We obtain immediately

$$
\frac{d c^{C}}{d \theta}>0
$$




\section{Appendix 3}

\section{Rule of law variables:}

Kaufrul: Rule of law; source: Kaufmann, D., Kraay, A. and Zoido-Lobaton, P. 1999a, "Aggregating Governance Indicators", Washington DC, United States: World Bank. Mimeographed document N =164; based on indices for 1997 and 1998.

Prslor9 : law and order: strength and impartiality of the legal system and degree of popular observance of the law; source: PRS-ICRG (Political Risk Service, International Country Risk Guide), $\mathrm{N}=130$.

\section{Corruption variables:}

Ticorr9 : 1998 Transparency International synthetic index, $\mathrm{N}=79$.

Kaufcor: Kaufmann et al. 99, N = 153; based on indices for 1997 and 1998.

\section{Instruments for corruption:}

Openness: Imports over GNP 1998, from World Bank World Development Indicators, $\mathrm{N}=151$.

Index of price distortions: Aggregated indicator of price distortions constructed by the method of principal components with two indices indicating the degree of price control in the economy and the exchange rate black market premium. Source: Freedom House, Higher score indicates less distortions, $\mathrm{N}=119$.

\section{Control variable:}

GNP9 : 1998 GNP per capita in current US dollars, from World Bank 2000 World Development Indicators. (GNP is GDP plus net receipts of primary income from nonresident sources). 


\section{REFERENCES}

Aubert C., and J.J. Laffont (2001), "Multiregulation in Developing Countries", mimeo IDEI.

Baron, D. and D. Besanko (1984), "Regulation, Asymmetric Information and Auditing", Rand Journal of Economics, 15, 267-302.

Becker, G. (1968), "Crime and Punishment: An Economic Approach", Journal of Political Economy, 76, 169-217.

Becker, G. and G. Stigler (1974), "Law Enforcement, Malfeasance, and Compensation of Enforcers", Journal of Legal Studies, 3, 1-19.

Bester, H. and R. Strausz (2000), "Contracting with Imperfect Commitment and the Revelation Principle: The Single Agent Case", mimeo, Free University Berlin.

Border, K. and J. Sobel (1987), "Samurai Accountant: A Theory of Auditing and Plunder", Review of Economic Studies, 54, 525-540.

Cremer, H., M. Marchand and P. Pestieau (1990), "Evading, Auditing and Taxing: The Equity-Compliance Trade-Off", Journal of Public Economics, $43,67-92$.

Gale, D. and M. Hellwig (1985), "Incentive-Compatible Debt Contracts: The One Period Problem", Review of Economic Studies, 52, 647-663.

Haggarty, L. and M. Shirley (1999), "Telecommunication Reform in Ghana", mimeo, World Bank.

Johnson, S., D. Kaufmann and P. Zoido-Lobaton (1999), "Corruption, Public Finances and the Unofficial Economy", Policy Research Working Paper 2169, The World Bank.

Khalil, F. (1992), "Auditing without Commitment", DP 92-15, University of Washington.

Krasa, S. and A. Villamil (2000), "Optimal Contracts when Enforcement is a Decision Variable", Econometrica, 68, 119-134.

Laffont, J.J. (1996), "Regulation, Privatization and Incentives in Developing Countries", in M.G. Quibria and J.M. Dowling, eds., Current Issues in Economic Development, Oxford University Press, Oxford.

Laffont, J.J. (1999), "Competition, Information and Development", in B. Plescovic and J. Stiglitz, eds., Annual World Bank Conference on Development Economics 1998, The World Bank, Washington D.C.

Laffont, J.J. and J. Tirole (1992), "Cost Padding, Auditing and Collusion", Annales d'Economie et Statistique, 25-26, 205-226.

Laffont, J.J. and J. Tirole (1993), A Theory of Incentives in Procurement and Regulation, MIT Press, Cambridge.

Mookherjee, D. and I. Png (1989), "Optimal Auditing, Insurance and Redistribution", Quarterly Journal of Economics, 104, 399-415. 
Ordover, J., R. Pittman and P. Clyde (1994), "Competition Policy for Natural Monopolies in a Developing Market Economy", Economics of Transition, 2, 317-343.

Polinsky, A.M. (1983), An Introduction to Law and Economics, Little Brown, Boston.

Posner, R. (1972), Economic Analysis of Law, Little, Brown and Company, Boston.

Schneider, F. and D. Enste (2000), "Shadow Economies: Size, Causes, and Consequences", Journal of Economic Literature, 38(1), 77-114.

Stigler, G. (1970), "Optimum Enforcement of Laws", Journal of Political Economy, 78, 526-536.

Townsend, R. (1979), "Optimal Contracts and Competitive Markets with Costly State Verification", Journal of Economic Theory, 21, 1-29. 